\title{
Long Memory Property and Structural Breaks in Volatility: Evidence from Turkey and Brazil
}

\author{
Samet Günay ${ }^{1}$ \\ ${ }^{1}$ Department of Banking and Finance, School of Applied Sciences, Istanbul Arel University, Istanbul, Turkey \\ Correspondence: Samet Günay, Department of Banking and Finance, School of Applied Sciences, Istanbul Arel \\ University, Istanbul, Turkey. Tel: 90-212-867-2500-1187. E-mail: dr.sgunay@gmail.com
}

Received: August 29, 2014

Accepted: September 22, 2014

Online Published: November 25, 2014

doi:10.5539/ijef.v6n12p119

URL: http://dx.doi.org/10.5539/ijef.v6n12p119

\begin{abstract}
In this study, we examined the long memory property of conditional variance of the BIST100 and the BOVESPA indexes considering the existence of structural breaks in the series. Results of the study will also be important from the Efficient Market Hypothesis perspective. Empirical analysis was conducted via FIGARCH, HYGARCH, GPH and modified GPH method of Phillips. As the results may be spurious in the existence of structural breaks, we performed all long memory tests before and after the Bai-Perron multiple structural breaks analysis. The sequential method of Bai-Perron multiple structural breaks analysis indicated 3 and 4 breaks for the BIST100 and the BOVESPA indexes, respectively. By considering this information we adjusted both index returns following the method of Choi et al. (2010) and performed the previous tests once again. According to the final results, conditional variance of both indexes have long memory property, that is, both of index volatilities are foreseeable under the past price information. This information conflicts with the weak form of the Efficient Market Hypothesis.
\end{abstract}

Keywords: long memory, structural breaks, market efficiency, emerging markets

\section{Introduction}

It can be said that theories for the price processes of financial assets emerged over one hundred years ago. These theories have been generally structured under the random walk model. However, Mandelbrot (1963) who is the father of fractals, drew attention to self-similarity in the financial time series, and then provided new tools in financial modelling using self-similarity, long-memory and fractal dimension. Mandelbrot is considered the first person who criticized the traditional finance theory, which is based on the Fama's $(1965,1970)$ Efficient Market Hypothesis and random walk theory, by pointing out the weak sides and deficiencies of it. It is not possible to expect the proceeding of traditional finance theory with old methods after Mandelbrot's studies.

During the period of 1952-1973, seminal papers of the traditional theory, which are the Modern Portfolio Theory (Markowithz, 1952), the Capital Asset Pricing Model (Sharpe, 1964), the Efficient Market Hypothesis, henceforth EMH, (Fama, 1970), and Black-Scholes Option Pricing Model (Black \& Scholes, 1973), accepted either the normal distribution of the return series or the assumption of the random walk of prices. However, a lot of studies showed that these assumptions are not valid under the real structure of financial markets. Financial asset return distributions are skewed, lepto-kurtic and may have a fat tail. On the other hand, they show long memory and self-similarity features. Just as traditional theory, which was based on the study of Bachelier (1900), fractal theory was put forward to serve as an alternative to the traditional theory, by Mandelbrot's studies (1963, 1972, 1983). Proposed approximation by Mandelbrot is the process that considers long memory and self-similarity in modelling. Mandelbrot and other researchers, who were inspired by his studies, created new and alternative models to be used in nearly every part of traditional finance theory. These models can be summarized as follows:

- Fractal Market Hypothesis instead of Efficient Market Hypothesis;

- Fractal distributions instead of normal distribution;

- Fractal Brownian motion instead of geometric Brownian motion;

- Fractal option pricing model instead of Black-Scholes option pricing model. 
The most important part of these new approaches is to take long memory property into account in the modeling of financial time series. The long memory property, which was originally introduced and modeled by Mandelbrot through Hurst exponent H, was defined differently by Hosking (1981) and Granger and Joyeux (1980) via differencing parameter $\mathrm{d}$ using a parametric way. In the next decade, these early studies have opened a new gate for the rise of FIGARCH model family. On the other hand, it has been stated in many studies that structural breaks may cause spurious long memory features; as exemplified by Smith (2005), Baillie and Morana (2009). By considering this criticism and using Bai-Perron's (2003) structural breaks test in this study, we examined the long memory features of two emerging markets' volatilities; Brazil and Turkey. Also, in order to increase the credibility of the obtained results, we perform semi-parametric (GPH and modified GPH) and parametric tests (HYGARCH and FIGARCH) together in the empirical section. Because, if the assumptions of parametric models are not satisfied results will not be credible. In addition to the model variety, we also use different type of distributions as preferred distributions may effect the results of the parametric models. Therefore, we test four distribution types: student- $t$, skewed student- $t$ and generalized error distribution in conjunction with the normal distribution in the construction of HYGARCH and FIGARCH models and we identify the best fitting distribution in the model process.

\section{Literature Reviews}

The long memory property has earned a great deal of interest in modern finance literature. The first study in the long memory topic was conducted by British hydrologist Hurst (1951), in order to measure the memory structure of the Nile river. Afterwards, Mandelbrot (1972) extended the methodology to the financial time series. He proposed the $R / S$ analysis in the calculations of long memory properties, and named $H$, the measurement in honour of Hurst.

After the seminal papers of Hurst and Mandelbrot, long memory studies focused on two sides: conditional mean and conditional variance. While Granger (1980, 1981), Granger and Joyeux (1980), and Hosking (1981) analysed the long memory property of the conditional mean via a new model, ARFIMA. Baillie et al. (1996) introduced a new class of GARCH processes, FIGARCH, to test long memory in the conditional variance.

Following these papers, evidence of long memory in return and volatility has been documented in many studies such as Ding et al. (1993), Crato and Lima (1994), Bollerslev and Mikkelsen (1996), Andersen and Bollerslev (1997). While general interest is in stock returns, some studies performed the long memory analysis in different areas. For example, Guillaume et al. (1997) presented stylized facts concerning the spot intra-daily foreign exchange markets. Similarly, Lien and Yang (2010) tested the effects of structural breaks and long memory on currency hedging. While Chung et al. (2003) analysed long memory in currency futures volatility, Barkoulas and Baum (1997) tested for long memory in the daily return series on Eurocurrency deposits denominated in Japanese yen. In addition to these studies Comte and Renault (1998) and Ohanissian et al. (2004) examined the effects of the long memory property in option pricing. In addition, Comte and Renault (1998) also studied a classical extension of the Black and Scholes Model for option pricing, often known as the Hull and White Model.

In conjunction with these papers, many researchers have proposed new methods, especially as extensions of the FIGARCH models. For example, Davidson (2004) proposed HYGARCH model that permits both the existence of second moments, and more extreme amplitudes than the simple IGARCH and FIGARCH models permit. Baillie and Morana (2007) introduced the Adaptive FIGARCH (A-FIGARCH) model which is designed to account for both long memory and structural breaks in the conditional variance process. On the other hand Kılıç (2011) introduced a new nonlinear long memory volatility process, denoted by Smooth Transition FIGARCH, or STFIGARCH, which was designed to account for both long memory and nonlinear dynamics in the conditional variance. Breidt et al. (1998) proposed a new time series representation of persistence in conditional variance called a long memory stochastic volatility (LMSV) model.

While the above papers were concerned with the underlying causes of long memory, in recent years there has been numerous research on the structural break effects in long memory. Within this period, some new models were created, and also some existing methods were modified to accommodate this feature, e.g. Baillie and Morana's (2007) A-FIGARCH and Smith's (2005) GPH model. Diebold and Inoue (2000) stated that long memory and structural breaks are intimately related. Andreou and Ghysels (2002) studied the size and power of the new tests for detecting breaks in the conditional variance, under various realistic univariate heteroscedastic models, change-point hypotheses and sampling schemes. Using Robinson's (1994) procedure with level shift dummies, Balcilar (2003) arrived at the surprising conclusion for the Turkish inflation rates that structural breaks significantly affect the long memory properties of the inflation series, and cause spurious long memory. Similarly, 
Granger and Hyung (2004) stated that part of the long memory may be caused by the presence of neglected breaks in the series. Han (2011) explored the issue of structural breaks and long memory property in the conditional variance process of the Korean exchange rates via A-FIGARCH model of Baillie and Morana (2007). Shi and Ho (2013) proposed a two-stage 3S-FIGARCH model as a new approach to detect the structural breaks. Zhang et al. (2007) developed a practical implementation of the test to distinguish between a shift in the volatility of returns, and long memory in squared returns. As it can be seen from the previous results, it may be necessary to consider both the structural breaks and the long memory property in the conditional variance process. That is why in this study we will use Bai-Perron multiple breaks point analysis to take structural breaks into account.

Even though there is an increasing interest in the long memory modelling for Turkey's financial markets, we have seen that these studies do not consider the structural breaks, with a few exceptions such as Balcilar (2003), Ural and Küçüközmen (2011) and Cevik and Erdogan (2009). The rest of the studies used various methods in the modelling of long memory. Kılıç (2004) showed the existence of long memory in the conditional variance of the BIST100 index via FIGARCH and semi-parametric methods, however there was no sign of long memory in the conditional mean. Similarly, Cevik and Emec (2013) investigated the persistence of the unexpected shocks on the Turkey financial market, and long lasting effects of Arab Spring via ARFIMA-FIGARCH model using the Chung model with student- $t$ distribution. Kasman et al. (2009) investigated the presence of long memory in the eight Central and Eastern European (CEE) countries' stock markets, using the ARFIMA, GPH, FIGARCH and HYGARCH models. Differently from previous papers, in order to test the long memory structure of $\$ / T L$ currency rate, Alptekin (2006) used non parametric methods such as modified R/S, modified variance V/S statistic and KPSS test. Gürsakal (2010) investigated whether the Turkish stock markets volatility exhibits different patterns of persistence in bulls and bears phases using Pagan and Sossounov (2003) algorithm and the Wavelet methods. Ural and Küçüközmen (2011) examined dual long memory properties for S\&P500, FTSE100, DAX, CAC40 and ISE100 returns by using the joint ARFIMA-FIGARCH model, and in the structural breaks test.

The rest of this paper is organized as follows; Section 3 describes theoretical methodology that is used in the empirical part. Section 4 discusses the findings from empirical tests before and after the structural break analysis. Finally, Section 5 presents the conclusion.

\section{Methodology}

Before we introduce the FIGARCH, HYGARCH, GPH and the modified GPH models, which will be used in the econometric analysis, first we give a short information concerning long memory property below.

The time series $y_{t}$ is a long memory process if its spectral density function satisfies:

$$
f(\lambda) \sim c|\lambda|^{-2 d} \text { as } \lambda \rightarrow 0
$$

for a positive finite $c$, and $-0.5<d<0.5$. For $d>0.5$, the time series $y_{t}$ is nonstationary, while for $d<-0.5$ it is noninvertible (Chambers, 1998). The same process can also be explained by the Hurst exponent (or self similarity parameter):

$$
f(\lambda) \sim c|\lambda|^{1-2 H} \text { as } \lambda \rightarrow 0
$$

It is clear that $H$ has a relationship with the fractional differencing parameter, $d$. The relationship between $d$ and $H$ can be defined in a simple way as follows: $d=\mathrm{H}-0.5$ (Wang, 2006). Baillie (1996) explained the long memory process in a different way, for a time series $y_{t}$ with the autocorrelation function $\rho_{j}$ at $\operatorname{lag} j$ as follows:

$$
\lim _{n \rightarrow \infty} \sum_{j=-n}^{n}\left|\rho_{j}\right|
$$

Fractionally integrated processes are long memory processes, given the definition in Eq. (3). Principally, the process $y_{t}$ can be shown as $I(d)$, if:

$$
(1-L)^{d} y_{t}=u_{t}
$$

where $L$ is the lag operator, $-0.5<d<0.5$ and $u_{t}$ is stationary.

While the autocorrelation function of the short memory process decays at an exponential rate (geometrically), contrastingly the long memory function decays hyperbolically. Hyperbolic and geometric functions can be shown in the following equations, respectively (Dacorogna et al., 2001):

$$
f_{h}(\lambda) \sim c|\lambda|^{-2 d} \text { and } f_{g}(\lambda) \sim c|\lambda|^{-\lambda / 2 d}
$$

When $d$ is between 0 and 0.5 , resistence or dependence will exist; higher $d$ values mean higher dependence. However in the case of $-0.5<d<1$, there will be the mean reverting long memory process (Mishra \& Urbain, 
2004). The relationship between $H$ and $d$ can be illustrated in the following example:

Table 1. Relationship between $H$ and $d$

\begin{tabular}{lcc}
\hline The process of Time Series & $H$ Value & $d$ Value \\
\hline Mean reverting process & 0,3 & -0.2 \\
Random Walk (Short Memory) & 0,5 & 0 \\
Long Memory & 0,7 & 0,2 \\
\hline
\end{tabular}

The path for a financial time series that will follow in different $H$ values can be shown by the graphs, below:
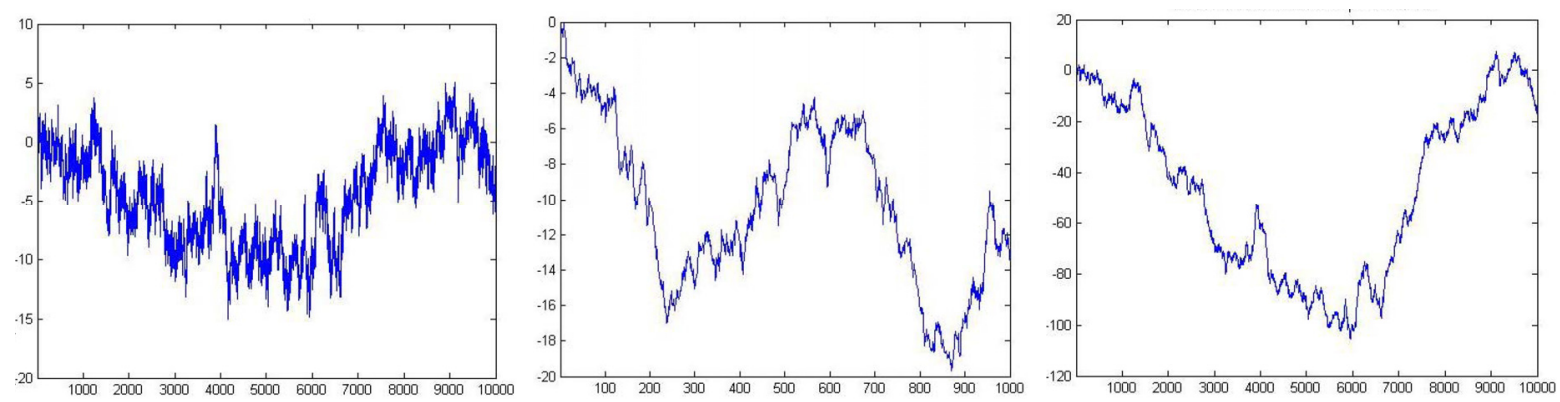

Figure 1. Fractional Brownian Motion for different $\mathrm{H}$ values $(\mathrm{H}=0.3, \mathrm{H}=0.5$ ve $\mathrm{H}=0.7)$

Source: http://math.arizona.edu/ flaschka/Topmatter/527files/termpapers/bole.pdf.

\subsection{FIGARCH Model}

Although stationary is a very important topic in econometrics modelling, using differencing to obtain the stationary financial time series may cause information loss in the original data. Generally it is seen that the financial time series becomes stationary at $I(1)$ level. Nevertheless, Granger (1980, 1981), Granger and Joyeux (1980), and Hosking (1981) showed the fractional stationary that is the long memory process, $I(d)$. However, the concept of long memory and the non-parametric methods in the measuring long memory were introduced for the first time by Hurst (1951) and Mandelbrot and Van Ness (1968); Granger (1980, 1981), Granger and Joyeux (1980), Hosking (1981) and Baillie et al. (1996) extended this issue to the parametric methods such as ARFIMA and FIGARCH.

Contrary to the $I(1)$ or the $I(0)$ time series, shocks to an $I(d)$ time series $(0<d<1)$ decay very slowly with a hyperbolic rate. Any shock concerning to conditional variance in FIGARCH models is not perpetual, it disappears in a hyperbolic rate (Bollerslev \& Mikkelsen, 1996).

Baillie et al. (1996) showed that the $\operatorname{FIGARCH}(p, d, q)$ process for $\left(\varepsilon_{t}\right)$ can be defined by:

$$
\phi(L)(1-L)^{d} \varepsilon_{t}^{2}=\omega+[1-\beta(L)] v_{t}
$$

where $0<d<1$, and all the roots of $\phi(L)$ and $[1-\beta(L)]$ lie outside the unit circle. Rearranging the terms in Eq. (6), an alternative representation for the $\operatorname{FIGARCH}(p, d, q)$ model is:

$$
[1-\beta(L)] \sigma_{t}^{2}=\omega+\left[1-\beta(L)-\phi(L)(1-L)^{d}\right] \varepsilon_{t}^{2}
$$

Thus, the conditional variance of $\varepsilon_{t}$ is simply given by

$$
\begin{gathered}
\sigma_{t}^{2}=\omega[1-\beta(l)]^{-1}+\left\{1-[1-\beta(l)]^{-1} \phi(L)(1-L)^{d}\right\} \varepsilon_{t}^{2} \\
\sigma_{t}^{2} \equiv \omega[1-\beta(l)]^{-1}+\lambda(L) \varepsilon_{t}^{2}
\end{gathered}
$$

In order to well define FIGARCH $(p, d, g)$ process and to ensure that the conditional variance is positive for all $t$, the coefficients in the infinite ARCH representation in Eq. (8) must be nonnegative (Baillie et al. 1996).

\subsection{HYGARCH Model}

Davidson (2004) introduced a new model named HYGARCH, generalizing the FIGARCH, that can be covariance stationary while exhibiting hyperbolic memory. Li et al. (2013) stated that similar to the FIGARCH model, in the HYGARCH model, squared residuals decline hyperbolically. However, different from the FIGARCH, the HYGARCH model releases the unit-amplitude restriction, hence making it possible to have both 
characters of long memory volatility and covariance stationarity. Similar to the Conrad (2010) the HYGARCH models can be obtained by modifying Eq. (8)

$$
\phi(L)\left[(1-\tau)+\tau(1-L)^{d}\right] \varepsilon_{t}^{2}=\omega+[1-\beta(L)] v_{t}
$$

Differently from the classic FIGARCH model there is an additional parameter $(\tau \geq 0)$ in this model. In the case of $\tau=0$ (or $d=0$ ) HYGARCH nests the GARCH model, and similarly nests the FIGARCH model provided that $\tau=1$.

\subsection{GPH and Modified GPH Models}

As explained by Grau (2005) the GPH method is based on the slope of the spectral density function around the angular frequency $w=0$. The spectral regression is defined by:

$$
\ln \left\{I\left(w_{\lambda}\right)\right\}=a+b \ln \left\{4 \sin ^{2}\left(\frac{w_{\lambda}}{2}\right)\right\}+n_{\lambda} \lambda=I, \ldots, v
$$

where $I\left(w_{\lambda}\right)$ is the periodogram of the time series at the frequencies $w_{\lambda}=\frac{2 p \lambda}{T}$ with $\lambda=1, \ldots, \frac{T-1}{2}, T$ is the number of observations and $v$ is the number of Fourier frequencies included in the spectral regression. The least square estimate of the slope coefficent provides an estimation of $d$. Andrews and Guggenberger (2003) stated that the widely used log-periodogram regression estimator of the long-memory parameter $d$ proposed by Geweke and Porter-Hudak (1983) had been criticized because of its finite-sample bias. Hence, different types of modifications were performed on the classic GPH method. One of them was Phillips' modified GPH model (henceforth, $\left.\mathrm{GPH}_{\mathrm{P}}\right)(1999 \mathrm{a}, \mathrm{b})$. Phillips (1999a) pointed out that the prior literature on this semi-parametric approach does not address the case of $d=1$, or a unit root. As explained by Baum (2000) this weakness of the $\mathrm{GPH}$ estimator is solved by the $\mathrm{GPH}_{\mathrm{P}}$ model, in which the dependent variable is modified to reflect the distribution of $d$ under the null hypothesis that $d=1$. Phillips (1999a, 1999b) proposed the testing of the presence of long-memory when $d$ is $0.5<d<1$ which is described by Mishra and Urbain (2004) as follows:

$$
\ln I_{v P}\left(\lambda_{\zeta}\right)=\kappa-2 d \ln / 1-e^{i \lambda_{\zeta}} /+\gamma\left(\lambda_{\zeta}\right)
$$

where $\gamma\left(\lambda_{\zeta}\right)=a\left(\lambda_{\zeta}\right)+\ln \frac{I_{P}\left(\lambda_{\zeta} ; d\right)}{I_{v P}\left(\lambda_{\zeta}\right)}+O_{p}\left(\frac{1}{j^{1-d}}\right), \alpha\left(\lambda_{\zeta}\right)=\ln \left[\frac{I_{u}\left(\lambda_{\zeta}\right)}{f_{u}(0)}\right]$, and $\kappa=\ln f_{u}(0)$. GPH $\mathrm{F}_{\mathrm{P}}$ estimator of $d$ is obtained by regressing $\ln I_{v P}\left(\lambda_{\zeta}\right)$ on $\ln \left|1-e^{i \lambda_{\zeta}}\right|$ over frequencies $\lambda_{\zeta}$.

\subsection{Bai-Perron Multiple Break Points Model}

Bai-Perron $(1998,2003)$ presented the following multiple linear regression model with $m$ breaks and $m+1$ regimes:

$$
y_{t}=c_{j}+u_{t} \quad t=T_{j-1}+1, \ldots, T_{j}
$$

where $j=1, \ldots, m+1$. In this model, $y_{t}$ is the logarithmic realized volatility at time $t$; and $c_{j}$ is the mean of the logarithmic realized volatility. As explained by Choi et al. (2010) $u_{t}$ may be serial correlated and heteroskedastic. The break points $\left(T_{1}+1, \ldots, T_{m}\right)$ are explicitly treated as unknown. Using this methodology we will estimate the unknown regression coefficients together with the break points.

Bai-Perron $(1998,2003)$ offered three different test statistics in order to determine multiple breaks:

- the $\operatorname{supF}$ type test of no structural break $(m=0)$ versus $m=k$ breaks

- $l$ versus $l+1$ breaks, labelled $\operatorname{supF}_{T}(l+1 \mid l)$

- double maximum tests: $\left(U D \max F_{T}(M, q)\right.$ and $\operatorname{WD} \max F_{T}(M, q)$

Test results present three different information criteria, BIC, LWZ and sequential estimates. The method suggested by Bai-Perron (2003) is based on the sequential application of the $\sup _{T}(l+1 \mid l)$ test because of the spurious results of BIC and LWZ tests in the existence of the serial correlation in the errors.

\section{Emprical Analysis}

\subsection{Descriptive Statistics and Data Analysis}

This paper examines both the structural breaks, and the long memory property in the squared returns of the BIST100 index and Bovespa, henceforth sbist and sbovespa, during the period of 02/01/1995-02/02/2014 via FIGARCH, HYGARCH, GPH and $\mathrm{GPH}_{\mathrm{P}}$ methods considering structural breaks with the Bai-Perron Multiple Structural Breaks Test. Detecting long memory properties in conditional variance means that future movements of volatility can be predicted. This situation requires the criticism of Fama's (1970) weak form of EMH. Because 
the weak form of EMH is based on the Random Walk hypothesis, it means that the current asset prices reflect all of the past historical price information within the security.

In this study, all data was provided by the database of the Central Bank of Republic of Turkey, and finance.yahoo.com. The best volatility modelling issues have been discussed deeply in finance literature. Pagan and Schwert (1990) stated that the most popular data in volatility modelling are squared and absolute returns. Triacca (2007) used squared returns, whereas Giles (2008) preferred absolute returns in the modelling of implied volatility. As it gives more reliable results in volatility modelling, we used squared returns in the empirical part. Squared returns obtained in following way: $R_{t}=\left[\ln \left(\frac{P_{t}}{P_{t-1}}\right)\right]^{2}$, where $R_{t}$ is the return at time $t$ and $P_{t}$ is the index price in time $t$.

Foremost, in order to get a general idea about the character of data, we calculated the descriptive statistics. Results showed that both of the series indicate deviations from normal distribution. A normal distribution has a symmetrical bell-shaped curve structure, and according to normal distribution's third and fourth moments, skewness and kurtosis values have to become 0 and 3, respectively. In the case of deviations from these figures, it means that related series do not show normal distribution properties.

Table 2. Descriptive statistics

\begin{tabular}{lcc}
\cline { 2 - 3 } Tests & sbist & sbovespa \\
\cline { 2 - 3 } Observations & 4872 & 4872 \\
Mean & 0.000121 & $9.05 \mathrm{E}-05$ \\
Median & $3.02 \mathrm{E}-05$ & $2.11 \mathrm{E}-05$ \\
Maximum & 0.007528 & 0.015679 \\
Minimum & 0.000000 & 0.000000 \\
Std. Dev. & 0.000332 & 0.000363 \\
Skewness & 9.099303 & 23.57426 \\
Kurtosis & 130.2487 & 841.4969 \\
Jarque-Bera & $3344616^{* *}$ & $1.43 \mathrm{E}+08^{* *}$ \\
\hline
\end{tabular}

Note. ${ }^{*}$ and ${ }^{* *}$ indicates the $95 \%$ and $99 \%$ confidence level, respectively.

As it is seen from the skewness and kurtosis values from Table 2, both of the series are positively skewed and leptokurtic. Positively skewed means that the right tail of distribution is longer than the left one. That is, negative return frequencies occur much more than positive returns. According to the Jerque Bera Test statistic, both sbist and sbovespa variables do not display normal distribution. These results demonstrate the general properties of the distribution of financial time series, such as fat and long tails. Before we performed the long memory tests, we tested the unit root structures of the series via the Augmented Dickey-Fuller (ADF) and Phillips-Perron (PP) Tests. Null hypothesis of these tests stated that there is unit root in the series; meaning the series is not stationary. Results show that the stationary level of both series are $I(0)$; that is, both of the data is stationary and does not have a unit root.

Table 3. Unit root tests

\begin{tabular}{cccccc}
\hline Variables & Tests & Intercept & Trend and Intercept & None & Level of Stationary \\
\hline \multirow{2}{*}{ sbist } & ADF Testi & $-22.04778^{* *}$ & $-22.97434^{* *}$ & $-9.463455^{* *}$ & $\mathrm{I}(0)$ \\
& PP Testi & $-68.55108^{* *}$ & $-65.46463^{* *}$ & $-77.96155^{* *}$ & $\mathrm{I}(0)$ \\
sbovespa & ADF Testi & $-19.52844^{* *}$ & $-19.87497^{* *}$ & $-13.75909^{* *}$ & $\mathrm{I}(0)$ \\
& PP Testi & $-77.58919^{* *}$ & $-76.13933^{* *}$ & $-83.72024^{* *}$ & $\mathrm{I}(0)$ \\
Note. ${ }^{*}$ and $^{* *}$ indicates the 95\% and 99\% confidence level, respectively.
\end{tabular}

After unit the root tests, we applied the Ljung-Box $Q$ Test in order to have an idea about the dependency structure of the series. The null hypothesis of this test can be written as follows, $H_{0}: \rho_{1}=\rho_{2}=\cdots=\rho_{p}=0$. This means that the data is independently distributed. Any autocorrelation value, that is different from zero, is a sign of the series' time dependency and memory. Accordingly, we rejected the null hypothesis for both of the series. It can be seen from Table 4 that all lag levels are statistically significant. 
Table 4. Ljung-Box $Q$ test of squared returns

\begin{tabular}{lcc}
\hline Lag Levels & sbist & sbovespa \\
\hline Q-Statistic (5) & $110.589^{* *}$ & $196.875^{* *}$ \\
Q-Statistic (10) & $118.887^{* *}$ & $283.440^{* *}$ \\
Q-Statistic (20) & $134.022^{* *}$ & $335.133^{* *}$ \\
Q-Statistic (50) & $174.026^{* *}$ & $454.791^{* *}$ \\
Q-Statistic (100) & $201.697^{* *}$ & $462.476^{* *}$ \\
\hline
\end{tabular}

Note. Lag levels of Q statistics are within the paranthesis. ${ }^{*}$ and ${ }^{* *}$ indicates the $95 \%$ and $99 \%$ confidence level, respectively.

On the other hand, we can attain similar results from the following graphs that show resistive autocorrelation structures of sbist and sbovespa variables, respectively. It is clear that autocorrelation functions of the series decay slowly. The results are an important finding for the dependency property of the volatility of the data.

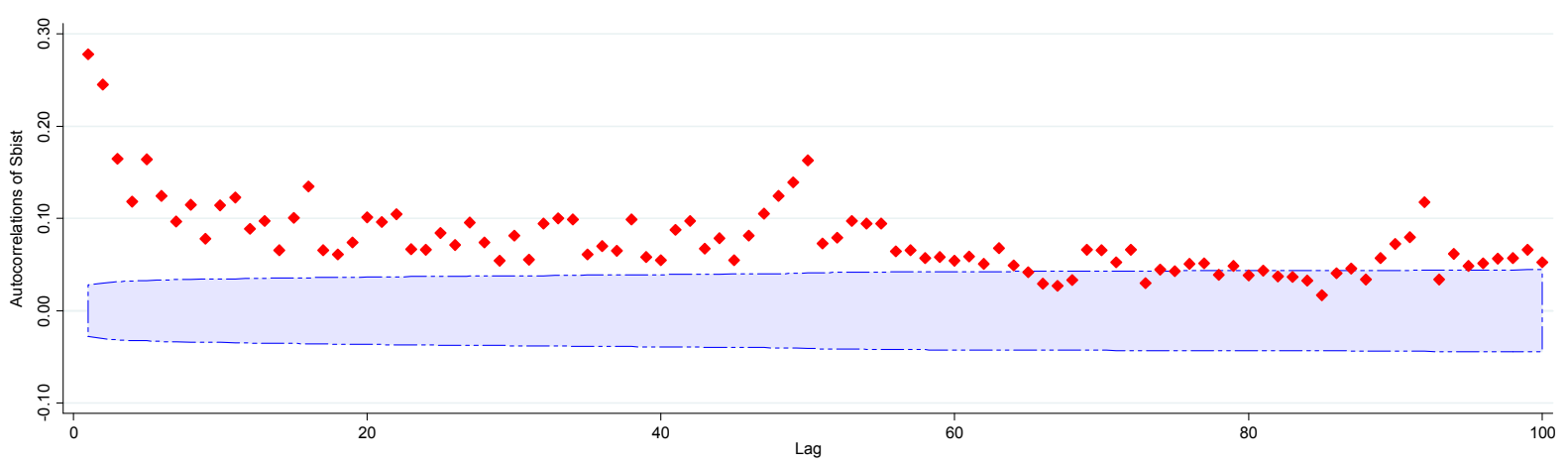

Figure 2. Autocorrelation function and confidence intervals of sbist variable

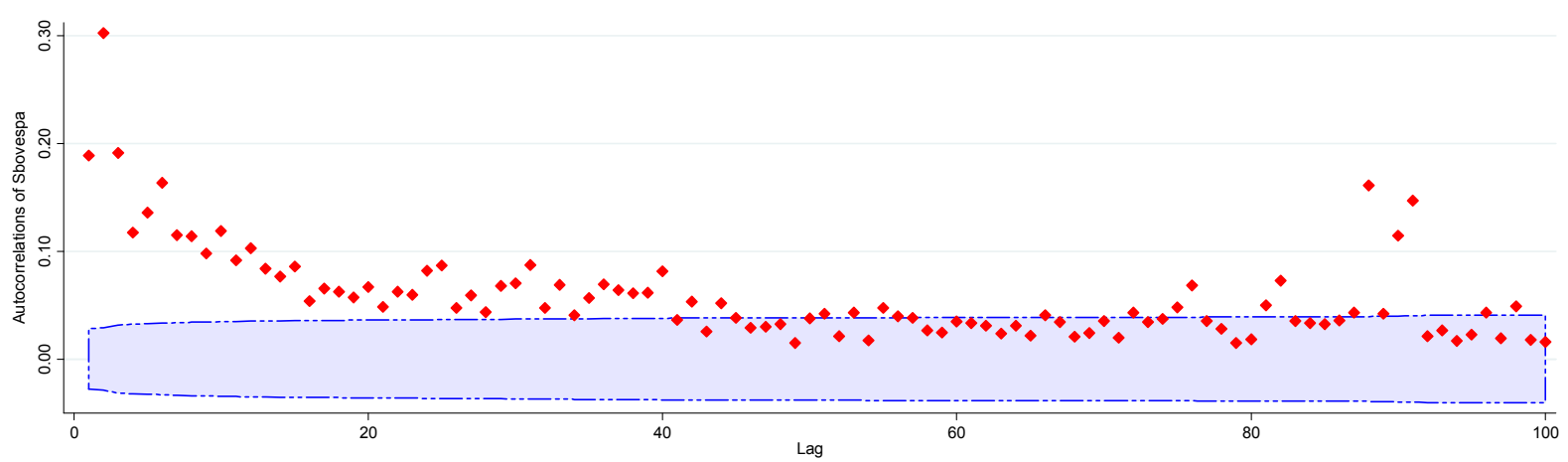

Figure 3. Autocorrelation function and confidence intervals of sbovespa variable

\subsection{Long Memory Analysis in Volatility Before B-P Test}

Similar to Davidson (2004), Niquez and Rubia (2006) Kasman et al. (2009) and Antonakakis and Darby (2013) we will perform FIGARCH and HYGARCH tests in order to investigate. We will also use GPH and $\mathrm{GPH}_{\mathrm{P}}$ methods in conjunction with the Bai-Perron multiple break points analysis in order to determine whether there is long memory in the volatility of sbist and sbovespa series, or not. As log periodogram methodology is more flexible in the diagnostic tests as a semi-parametric method, we will support the FIGARCH and HYGARCH test results, with $\mathrm{GPH}$ and $\mathrm{GPH}_{\mathrm{P}}$ outputs before and after structural breaks analysis.

Descriptive statistics showed that the distribution shape of the data are quite different from the normal distribution. Therefore, we first determined the correct distribution type that fit the data using the Log-likelihood (LL) and the Akaike Information Criteria (AIC) as model selection criteria before we investigated long memory in the empirical part. As it can be seen from Table 5, in the FIGARCH and HYGARCH estimations, which were modelled under normal, student- $t$, skewed student- $t$ and generalized error distribution, the most succesful distribution type for the squared returns is generalized error distribution (GED). Because of its success we used 
GED in the following section as a reference distribution for the squared returns in the FIGARCH and HYGARCH models. Although we do not use absolute returns in the modelling, during the analysis of the return series we have seen that the absolute returns corresponded with the skewed student-t distribution in contrast to squared returns.

In order to exhibit the difference between the models' performance, we performed the GARCH test, which does not consider the long memory property, in conjunciton with the FIGARCH and HYGARCH models. After we tried different lags, we settled on the GARCH $(1,1)$ model. As it can be seen from Table 6 , the sum of the $\alpha$ and $\beta$ values were close to 1, especially for sbist data (0.9817). According to Engle and Bollerslev (1986) this is a sign of the resistence volatility process.

Table 5. Determination of distribution type

\begin{tabular}{lcccc}
\hline \multicolumn{1}{c}{ Methods } & \multicolumn{2}{c}{ sbist } & \multicolumn{2}{c}{ sbovespa } \\
\hline FIGARCH MODEL & $\begin{array}{c}\text { Log-likelihood } \\
\text { Criteria }\end{array}$ & $\begin{array}{c}\text { Akaike Information } \\
\text { Criteria }\end{array}$ & $\begin{array}{c}\text { Log-likelihood } \\
\text { Criteria }\end{array}$ & $\begin{array}{c}\text { Akaike Information } \\
\text { Criteria }\end{array}$ \\
Normal & 23884.680 & -9.802824 & 24456.796 & -10.037683 \\
Distribution & & & & \\
Student-t Distribution & 31525.880 & -12.939196 & 28397.114 & -11.654809 \\
Skewed Student-t & 32643.308 & -13.397499 & 32642.953 & -13.397353 \\
Distribution & & & & \\
Generalized Error & 34689.774 & -14.238002 & 35374.73 & 14.519186 \\
Distribution & & & & \\
HYGARCH MODEL & Log-likelihood & Akaike Information & Log-likelihood & Akaike Information \\
& Criteria & Criteria & Criteria & Criteria \\
Normal & 25922.923 & -10.639131 & 34563.598 & -14.186206 \\
Distribution & & & & \\
Student-t Distribution & 32693.322 & -13.418030 & 32208.872 & -13.219159 \\
Skewed Student-t & 32686.445 & -13.414797 & 32674.456 & -13.409875 \\
Distribution & & & & \\
Generalized Error & 35237.191 & -14.462312 & 36136.750 & -14.831589 \\
Distribution & & & & \\
\hline
\end{tabular}

Results of Table 6 indicate that the long memory parameter $d$ is statistically significant for all models. That is, it is significantly different from zero for the FIGARCH and HYGARCH models. It means that there is long memory property in the volatility of the squared returns of sbist and sbovespa data. Another important finding is the $\beta_{1}$ values of the FIGARCH and HYGARCH models becoming lower than those in the GARCH models.

Tablo 6. GARCH, FIGARCH and HYGARCH estimates

\begin{tabular}{|c|c|c|c|c|c|c|}
\hline & \multicolumn{3}{|c|}{ sbist } & \multicolumn{3}{|c|}{ sbovespa } \\
\hline & $\begin{array}{l}\text { GARCH } \\
(1, d, 1)\end{array}$ & $\begin{array}{c}\text { FIGARCH } \\
(1, d, 1)\end{array}$ & $\begin{array}{c}\text { HYGARCH } \\
(1, d, 1)\end{array}$ & $\begin{array}{l}\text { GARCH } \\
(1, d, 1)\end{array}$ & $\begin{array}{c}\text { FIGARCH } \\
(1, d, 1)\end{array}$ & $\begin{array}{c}\text { HYGARCH } \\
(1, d, 1)\end{array}$ \\
\hline$\omega$ & $\begin{array}{l}0.0007^{*} \\
(0.0003)\end{array}$ & $\begin{array}{l}0.0782^{* *} \\
(0.0022)\end{array}$ & $\begin{array}{l}0.0513^{* *} \\
(0.0001)\end{array}$ & $\begin{array}{l}0.2643^{* *} \\
(0.0112)\end{array}$ & $\begin{array}{l}0.0739^{* *} \\
(0.0022)\end{array}$ & $\begin{array}{l}0.0502^{* *} \\
(0.0012)\end{array}$ \\
\hline$d$ & - & $\begin{array}{l}0.4391^{* *} \\
(0.0417)\end{array}$ & $\begin{array}{l}0.4472^{* *} \\
(0,0001)\end{array}$ & - & $\begin{array}{l}0.4564^{* *} \\
(0.0417)\end{array}$ & $\begin{array}{l}0.4676^{* *} \\
(0.0391)\end{array}$ \\
\hline$\alpha$ & $\begin{array}{l}0.0695^{* *} \\
(0.0120)\end{array}$ & $\begin{array}{l}0.0988^{* *} \\
(0.0505)\end{array}$ & $\begin{array}{l}0.1101^{* *} \\
(0.004)\end{array}$ & $\begin{array}{c}0.0063 \\
(0.0085)\end{array}$ & $\begin{array}{l}0.1093^{* *} \\
(0.0505)\end{array}$ & $\begin{array}{l}0.1230^{* *} \\
(0.0411)\end{array}$ \\
\hline$\beta$ & $\begin{array}{l}0.9122^{* *} \\
(0.0132)\end{array}$ & $\begin{array}{l}0.4023^{* *} \\
(0.0145)\end{array}$ & $\begin{array}{c}0.3839^{* *} \\
(0.004)\end{array}$ & $\begin{array}{l}0.9124^{* *} \\
(0.0032)\end{array}$ & $\begin{array}{l}0.3883^{* *} \\
(0.0145)\end{array}$ & $\begin{array}{l}0.3672^{* *} \\
(0.0140)\end{array}$ \\
\hline G.E.D.(DF) & $\begin{array}{l}2.3366^{* *} \\
(0.1910)\end{array}$ & $\begin{array}{l}0.9487^{* *} \\
(0.0152)\end{array}$ & $\begin{array}{l}0.9969^{* *} \\
(0,0001)\end{array}$ & $\begin{array}{l}2.2935^{* *} \\
(0.1212)\end{array}$ & $\begin{array}{l}0.9267^{* *} \\
(0.0152)\end{array}$ & $\begin{array}{l}0.9727^{* *} \\
(0.0161)\end{array}$ \\
\hline Log Alpha (HY) & & - & $\begin{array}{l}-0.5246^{* *} \\
(0,0001)\end{array}$ & & - & $\begin{array}{l}-0.5294^{* *} \\
(0.0591)\end{array}$ \\
\hline $\ln (L)$ & 32479 & 34689 & 35237 & 26038 & 35374 & 36136 \\
\hline
\end{tabular}




\begin{tabular}{ccccccc}
\hline$A I C$ & -13.3310 & -14.2380 & -14.4623 & -10.6867 & -14.5191 & -14.8315 \\
$S I C$ & -13.3243 & -14.2300 & -14.4529 & -10.6801 & -14.5111 & -14.8222 \\
$Q(50)$ & $1423.07^{* *}$ & $1294.30^{* *}$ & $1342.14^{* *}$ & $2110.05^{* *}$ & $2066.46^{* *}$ & $1321.27^{* *}$ \\
$A R C H(5)$ & 0.1302 & $5.4855^{* *}$ & $73.435^{* *}$ & 1.2731 & $2.2076^{* *}$ & $1.1344^{* *}$ \\
\hline
\end{tabular}

Note. Standard errors are within the parenthesis. ${ }^{*}$ and ${ }^{* *}$ indicates the $95 \%$ and $99 \%$ confidence level, respectively. $\omega$ : constant of variance equation, $d$ : long memory coefficient, $\alpha$ : ARCH coefficient, $\beta$ : GARCH coefficient $\ln (L)$ : maximized value of the loglikelihood fonction, AIC: Akaike Information Criterion, SIC: Schwarz Information Criterion, ARCH (5) is the ARCH test statistic for 5 lag level, Q (20) is the Ljung Box test statistic for 50 lag level.

As well as the significant $d$ coefficient; log likelihood, AIC and SIC results show that the HYGARCH model is more succesful than the FIGARCH and GARCH models. That is, the HYGARCH model fits the data better than the other models. However, it is seen that there are some vulnerabilities of these models regarding the diagnostic tests results. As there is autocorrelation and heteroscadasticity in the residuals of the models, values of the $d$ coefficient may be spurious. Therefore, in the next section, we will perform semi-parametric tests, which are more flexible on the assumptions, in order to eliminate the uncertainties of the FIGARCH and HYGARCH models. Geweke and Porter-Hudak (1983) proposed the estimation of $d$ under the first $m$ periodogram ordinates; that is why we have used different periodogram levels, which are $T=0.5, T=0.6, T=0.7$, and $T=0.8$, under $\mathrm{GPH}$ and $\mathrm{GPH}_{\mathrm{P}}$ models. Results indicate that all obtained $d$ coefficents are statistically significant in the 95 percent confidence level. These results have supported the previous findings.

Table 7. Log-Periodogram analysis

\begin{tabular}{lllll}
\hline $\mathrm{GPH}$ & $v=\sqrt{T}$ & $v=T^{0.60}$ & $v=T^{0.70}$ & $v=T^{0.80}$ \\
\hline \multirow{2}{*}{ sbist } & $0.3546^{* *}$ & $0.2361^{* *}$ & $0.2400^{* *}$ & $0.2533^{* *}$ \\
& $(0.0788)$ & $(0.0448)$ & $(0.0313)$ & $(0.0212)$ \\
sbovespa & $0.1987^{*}$ & $0.2368^{* *}$ & $0.2523^{* *}$ & $0.2468^{* *}$ \\
\multirow{2}{*}{$\mathrm{GPH}_{\mathrm{P}}$} & $(0.0963)$ & $(0.0622)$ & $(0.0352)$ & $(0.0218)$ \\
\multirow{2}{*}{ sbist } & $v=\sqrt{T}$ & $v=T^{0.60}$ & $v=T^{0.70}$ & $v=T^{0.80}$ \\
& $0.3700^{* *}$ & $0.2533^{* *}$ & $0.2510^{* *}$ & $0.2603^{* *}$ \\
\multirow{2}{*}{ sbovespa } & $(0.0716)$ & $(0.0424)$ & $(0.0307)$ & $(0.0211)$ \\
& $0.1753^{*}$ & $0.2235^{* *}$ & $0.2507^{* *}$ & $0.2471^{* *}$ \\
\hline
\end{tabular}

Note. Standard errors are within the parenthesis. ${ }^{*}$ and ${ }^{* *}$ indicates the $95 \%$ and $99 \%$ confidence level, respectively.

So far, although the findings have shown the existence of the long memory property in the volatility of the BIST100 and BOVESPA indexes, we should consider structural breaks in the data to avoid spurious effects of level shifts. This is because long memory property can arise from financial crisis and corresponding policy changes, as well. Therefore, we performed multiple breakpoint analysis via the Bai-Perron Multiple Structural Breaks Test.

\subsection{Bai-Perron Multiple Structural Breaks Test}

Bai and Perron $(1998,2003)$ proposed three different test statistics $\left(\sup F, \sup F_{T}(l+1 \mid l)\right.$ and $\left.U D \max _{T}(M, q)-W D \max F_{T}(M, q)\right)$ for the structural breaks analysis. However, they recommended the $\sup F_{T}(l+1 \mid l)$ test as a final decision that is based on the sequential approximation. As the Asia Crisis 1997, Russia crisis 1998, Brazil crisis 1999, Turkey crisis 2001 and Mortagage crisis 2008 are within the period of the sample, while setting up the test model, we determined that the number of maximum breaks is five. According to the results, we rejected the null hypothesis of $\sup F_{T}(l)$ test, which says that there are no structural breaks against the alternative hypothesis, which claims that there are a maximum of 5 breaks for both the sbist and sbovespa variables in the $95 \%$ confidence interval. On the other hand, the null hypothesis of the $U D_{\max }$ and $W D_{\max }$ tests, which says that there are no structural breaks against the $m$ structural breaks, was rejected for $\alpha=0.05$, as well. In spite of that, we could not reject the null hypothesis of $\sup F_{T}(l+1 \mid l)$ test for $l=4$.

Bai and Perron (2003a) showed that the sequential test is more robust than the BIC and LWZ methods. Subsequently we prefered to use the sequential method results in order to determine the number of breaks. Hence, it was seen that while there were 3 breaks for the sbist variable, there were 4 breaks for the sbovespa variable. When we compare the break dates for the two countries, it is seen that except for the year 2009, there is no 
similarity between the countries. According to the results, the break dates of the sbist variable are 06/16/1994, 08/06/1998, and 04/14/2003; whereas for sbovespa variable they are 06/16/1994,07/31/1998,04/11/2003, and $06 / 05 / 2009$. In the presenting of the break dates via graphs, we used the raw and indexed squared returns in order to eliminate the effect of inflation in the period of the sample. As it can be seen from the figures below, the break dates seem more clear from the indexed series. In the calculating of the indexed series we used dollar/local currency value on $02 / 01 / 1995$.

Table 8. Bai-Perron multiple structural breaks test results

\begin{tabular}{|c|c|c|}
\hline Test Statistics & sbist & sbovespa \\
\hline $\sup F_{T}(1)$ & $102.8852^{* *}$ & $23.3377^{* *}$ \\
\hline $\sup F_{T}(2)$ & $39.1227^{* *}$ & $51.727^{* *}$ \\
\hline $\sup F_{T}(3)$ & $41.6774^{* *}$ & $40.1558^{* *}$ \\
\hline $\sup F_{T}(4)$ & $38.9079^{* *}$ & $33.0841^{* *}$ \\
\hline $\sup F_{T}(5)$ & $34.6075^{* *}$ & $24.7903^{* *}$ \\
\hline$U D_{\max }$ & $102.8852^{* *}$ & $51.727^{* *}$ \\
\hline$W D_{\max }$ & $102.8852^{* *}$ & $51.727^{* *}$ \\
\hline $\sup F_{T}(2 \mid 1)$ & $26.5703^{* *}$ & $72.6926^{* *}$ \\
\hline $\sup F_{T}(3 \mid 2)$ & $28.9579^{* *}$ & $12.8226^{* *}$ \\
\hline $\sup F_{T}(4 \mid 3)$ & $20.5716^{* *}$ & $33.549^{* *}$ \\
\hline $\sup F_{T}(5 \mid 4)$ & - & - \\
\hline \multicolumn{3}{|c|}{ Numbers of Breaks } \\
\hline $\mathrm{BIC}$ & 3 & 1 \\
\hline LWZ & 2 & 1 \\
\hline Seguential & 3 & 4 \\
\hline \multicolumn{3}{|l|}{ Break Dates } \\
\hline \multirow{2}{*}{$\widehat{T}_{1}$} & 08.04 .1998 & 01.27 .1999 \\
\hline & [11.18.1996-11.18.1998] & [01.27.1999-09.24.2001] \\
\hline \multirow{2}{*}{$\widehat{T}_{2}$} & 03.20 .2003 & 10.25 .2002 \\
\hline & {$[03.17 .2003-12.26 .2003]$} & [07.08.2002-01.09.2004] \\
\hline \multirow{2}{*}{$\widehat{T}_{3}$} & 05.07 .2009 & 08.02 .2006 \\
\hline & [08.26.2008-12.22.2010] & [02.08.2005-08.14.2006] \\
\hline \multirow{2}{*}{$\widehat{T}_{4}$} & 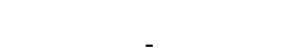 & 05.08 .2009 \\
\hline & - & [02.17.2009-11.18.2009] \\
\hline \multicolumn{3}{|c|}{ Estimations Of Mean For Each Regime } \\
\hline \multirow[t]{2}{*}{$\hat{c}_{1}$} & $1.3396 \mathrm{e}-004$ & 0.0084 \\
\hline & $(1.0717 \mathrm{e}-005)$ & $(2.5103 \mathrm{e}-004)$ \\
\hline \multirow[t]{2}{*}{$\hat{c}_{2}$} & $2.5396 \mathrm{e}-004$ & 0.0115 \\
\hline & $(9.4407 e-006)$ & $(2.1908 \mathrm{e}-004)$ \\
\hline \multirow[t]{2}{*}{$\hat{c}_{3}$} & $7.4042 \mathrm{e}-005$ & 0.0058 \\
\hline & $(8.1014 \mathrm{e}-006)$ & $(2.6775 \mathrm{e}-004)$ \\
\hline \multirow[t]{2}{*}{$\hat{c}_{4}$} & $4.4758 \mathrm{e}-005$ & 0.0069 \\
\hline & $(9.2216 \mathrm{e}-006)$ & $(2.7050 \mathrm{e}-004)$ \\
\hline$\hat{c}_{5}$ & - & $\begin{array}{c}0.0049 \\
(2.1573 \mathrm{e}-004)\end{array}$ \\
\hline
\end{tabular}

Note. ${ }^{*}$ and ${ }^{* *}$ indicates the $95 \%$ and $99 \%$ confidence level, respectively. Values are within the brackets denote confidence intervals of the break dates at $\% 90$. Values are within the parenthesis denote standard errors. 

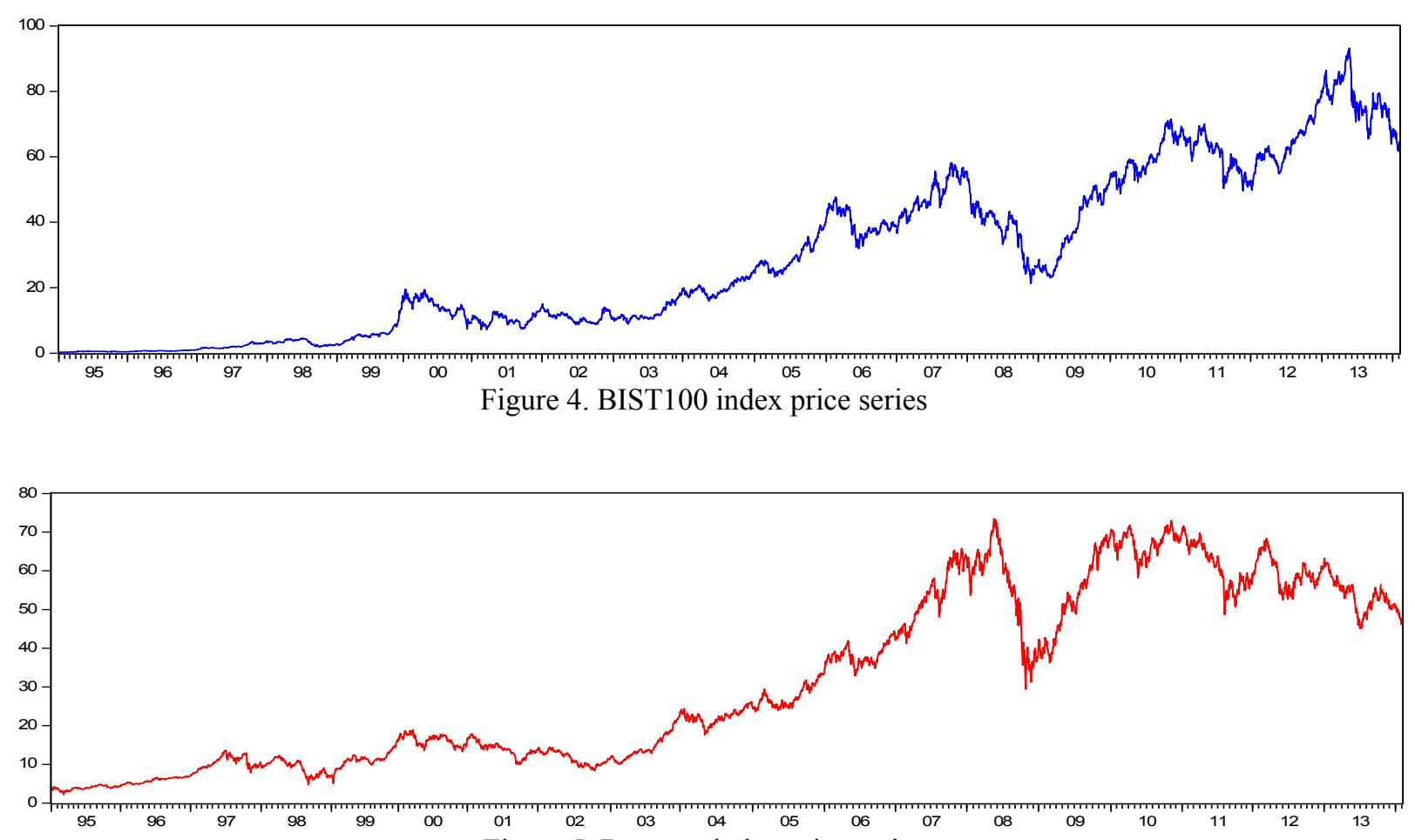

Figure 5. Bovespa index price series
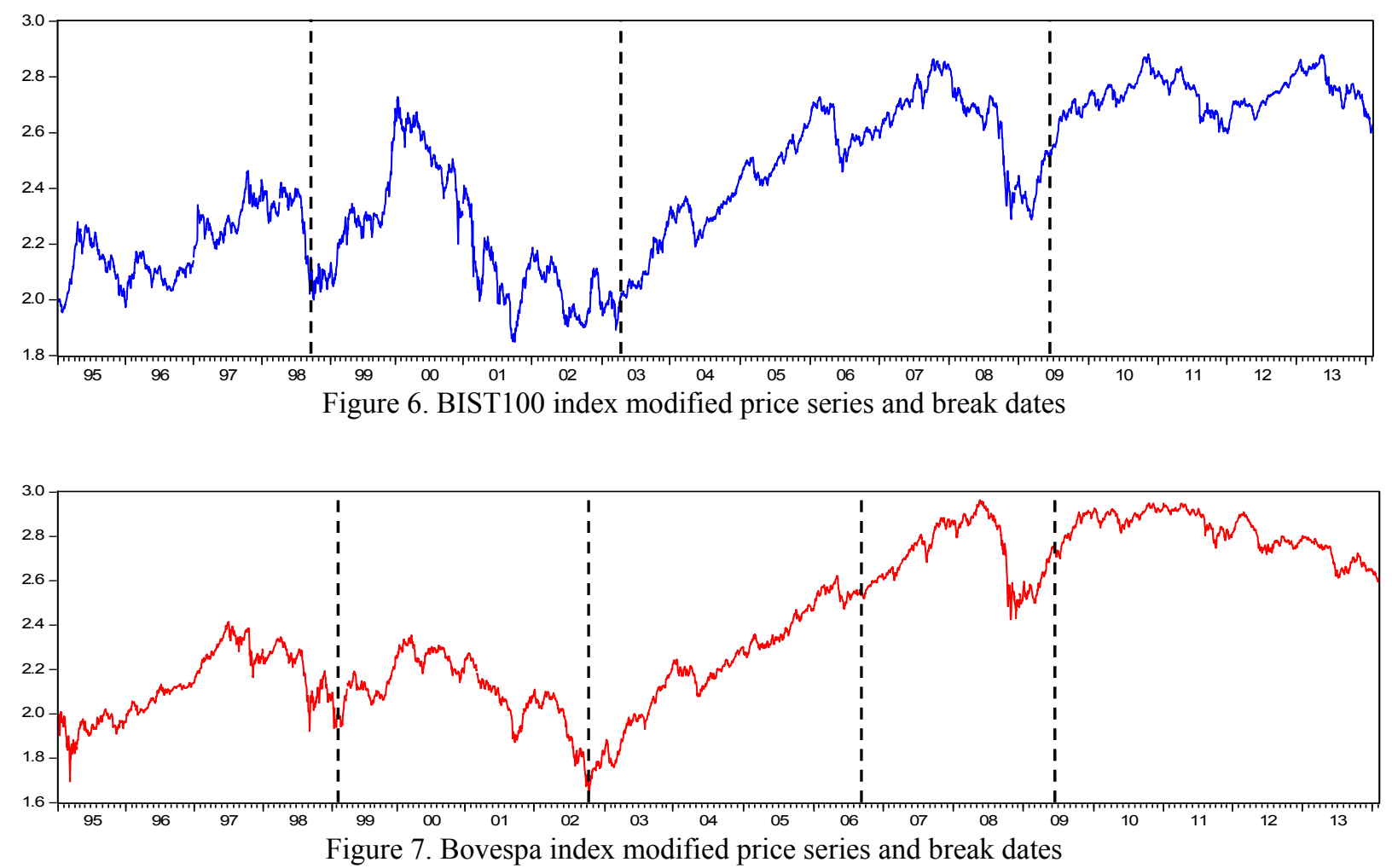

\subsection{Long Memory Analysis in Volatility After B-P Test}

After the confirmation of the structural breaks in the squared returns, we adjusted the series using the method of Choi et al. (2010) via the following equaiton: $\mathrm{u}_{t}=y_{t}-c_{j}$. Here, $c_{j}$ is the mean of the different regimes that were obtained from the break dates. $y_{t}$ is raw series and $\mathrm{u}_{t}$ is the adjusted series. Using this equation, we demeaned all of the series in each regime. In other words, we turned the different levels of the means in to one 
mean; thereby eliminating the effect of the breaks. FIGARCH, HYGARCH, GPH and $\mathrm{GPH}_{\mathrm{P}}$ test results were presented as the following for the adjusted series.

New results have verified the previous test outputs. As it can be seen from Table 9, all of the $d$ coefficients are statistically significant at the 95 percent confidence level. Besides, according to the log-likelihood and AIC statistics, the HYGARCH model presents the best performance again. Nevertheless, both the FIGARCH and HYGARCH models have failed at the diagnostic tests. That is why we need to confirm these test results using a reference test again.

Tablo 9. GARCH, FIGARCH and HYGARCH estimates

\begin{tabular}{|c|c|c|c|c|}
\hline & \multicolumn{2}{|c|}{ sbist } & \multicolumn{2}{|c|}{ sbovespa } \\
\hline & FIGARCH & HYGARCH & FIGARCH & HYGARCH \\
\hline & $(1, d, 1)$ & $(1, d, 1)$ & $(1, d, 1)$ & $(1, d, 1)$ \\
\hline & ged & ged & ged & ged \\
\hline \multirow{2}{*}{$\omega$} & $0.0783^{* *}$ & $0.0512^{* *}$ & $0.0739^{* *}$ & $0.0500^{* *}$ \\
\hline & $(0.0022)$ & $(0.0001)$ & $(0.0023)$ & $(0.0012)$ \\
\hline \multirow{2}{*}{$d$} & $0.4391^{* *}$ & $0.4468^{* *}$ & $0.4562^{* *}$ & $0.4674^{* *}$ \\
\hline & $(0.0417)$ & $(2.58 \mathrm{e}-008)$ & $(0.0432)$ & $(0.0390)$ \\
\hline \multirow{2}{*}{$\alpha$} & $0.0987^{* *}$ & $0.1090^{* *}$ & $0.1091^{* *}$ & $0.1227^{* *}$ \\
\hline & $(0.0505)$ & $(0.0041)$ & $(0.0308)$ & $(0.0410)$ \\
\hline \multirow{2}{*}{$\beta$} & $0.4023^{* *}$ & $0.3851^{* *}$ & $0.3885^{* *}$ & $0.3674^{* *}$ \\
\hline & $(0.0145)$ & $(0.0041)$ & $(0.0163)$ & $(0.0140)$ \\
\hline \multirow{2}{*}{ G.E.D.(DF) } & $0.9489^{* *}$ & $1.0176^{* *}$ & $0.9264^{* *}$ & $0.9727^{* *}$ \\
\hline & $(0.0152)$ & $(0.0001)$ & $(0.0176)$ & $(0.0160)$ \\
\hline Asymmetry & - & - & - & - \\
\hline Tail & - & - & - & - \\
\hline Log Alpha (HY) & - & $\begin{array}{c}-0.5135^{* *} \\
(2.43 \mathrm{e}-008)\end{array}$ & - & $\begin{array}{c}-0.5299^{* *} \\
(0.0584)\end{array}$ \\
\hline $\ln (L)$ & 34694. & 33983 & 35377 & 36142 \\
\hline$A I C$ & -14.2398 & -13.9475 & -14.5202 & -14.8337 \\
\hline SIC & -14.2318 & -13.9382 & -14.5122 & -14.8244 \\
\hline$Q(50)$ & $1254.35^{* *}$ & $868.861^{* *}$ & $2092.32^{* *}$ & $1335.28^{* *}$ \\
\hline$A R C H(5)$ & $5.2077^{* *}$ & $72.1190^{* *}$ & $2.3240^{* *}$ & $1.1849^{* *}$ \\
\hline
\end{tabular}

Note. Standard errors are within the parenthesis. ${ }^{*}$ and ${ }^{* *}$ indicates the $95 \%$ and $99 \%$ confidence level, respectively. $\omega$ : constant of variance equation, $d$ : long memory coefficient, $\alpha$ :ARCH coefficient, $\beta$ : GARCH coefficient $\ln (L)$ : maximized value of the loglikelihood fonction, AIC: Akaike Information Criterion, SIC: Schwarz Information Criterion ARCH (5) is the ARCH test statistic for 5 lag level, Q(20) is the Ljung Box test statistic for 50 lag level.

Table 10. Log-Periodogram analysis

\begin{tabular}{lcccc}
\hline $\mathrm{GPH}$ & $v=\sqrt{T}$ & $v=T^{0.60}$ & $v=T^{0.70}$ & $v=T^{0.80}$ \\
\hline \multirow{2}{*}{ sbist } & $0.3532^{* *}$ & $0.2310^{* *}$ & $0.2355^{* *}$ & $0.2577^{* *}$ \\
& $(0.077)$ & $(0.0448)$ & $(0.0305)$ & $(0.0217)$ \\
\multirow{2}{*}{ sbovespa } & $0.1981^{*}$ & $0.2376^{* *}$ & $0.2528^{* *}$ & $0.2477^{* *}$ \\
\multirow{2}{*}{$\mathrm{GPH}_{\mathrm{P}}$} & $(0.0964)$ & $(0.0625)$ & $(0.0353)$ & $(0.0218)$ \\
\multirow{2}{*}{ sbist } & $v=\sqrt{T}$ & $v=T^{0.60}$ & $v=T^{0.70}$ & $v=T^{0.80}$ \\
& $0.36799^{* *}$ & $0.2473^{* *}$ & $0.2460^{* *}$ & $0.2643^{* *}$ \\
\multirow{2}{*}{ sbovepsa } & $(0.0712)$ & $(0.0422)$ & $(0.0299)$ & $(0.0215)$ \\
& $0.1756^{*}$ & $0.2246^{* *}$ & $0.2515^{* *}$ & $0.2481^{* *}$ \\
\hline
\end{tabular}

Note. Standard errors are within the parenthesis. ${ }^{*}$ and ${ }^{* *}$ indicates the $95 \%$ and $99 \%$ confidence level, respectively.

In order to support the findings of the FIGARCH and HYGARCH models we performed GPH and modified $\mathrm{GPH}$ tests for the modified data. Table 10 presents the test results of the $\mathrm{GPH}$ and $\mathrm{GPH}_{\mathrm{P}}$ models. Outputs 
indicate that $d$ coefficients are statistically significant for $\alpha=0.05$ in both the GPH and $\mathrm{GPH}_{\mathrm{P}}$ models. All these findings are consistent with the results of HYGARCH and FIGARCH models. This means that there are long memory properties in both index volatilities.

\section{Conclusion}

The long memory issue has been one of the most interesting topics of financial econometrics in the last twenty years. However, the majority of these studies were conducted for developed countries' financial markets. In this study, we examined the long memory structure of the volatility of the BIST100 and BOVESPA Indexes before and after Bai-Perron multiple structural break analysis. After the determination of best fitting distribution for both return series, all long memory analysis were conducted via GPH, Modified GPH, HYGARCH ve FIGARCH models. Results showed that the best fitting distribution for the squared returns is the generalized error distribution, whereas the best fitting distribution for the absolute returns is the skewed student- $t$ distribution. These results are also accordant with the findings of literature, because many studies showed that financial asset returns have fat tails and these tails decay via a power law behaviour. Before the structural break analysis, GPH, Modified GPH, FIGARCH ve HYGARCH tests have demonstrated that both return volatilities have long memory features. However, as it is stated in the literature, structural breaks can produce spurious long range dependence effects. Hence, in the second part of the empirical section, we conducted the Bai-Perron multiple structural break point analysis for all the return series due to the existence of 5 serious financial crises in the period of the study: Turkey and Mexico in 1994, Asia in 1997, Russia in 1998, Turkey in 2001 and the mortgage crisis in 2008. As a matter of fact, results of the Bai-Perron multiple break point analysis showed that there is 4 and 3 breaks for the BIST100 and BOVESPA index volatilities, respectively. After the determination of the break dates, using the procedure suggested by Choi et al. (2010) we have modified all raw return series and performed the aforementioned tests again. New results also indicated that modified return series have long memory properties, as well. These findings proved that results of the first long range dependence tests are not spurious, that is, long memory property of the return volatilities does not arise from the structural breaks.

\section{References}

Alptekin, N. (2006). Long Memory Analysis of USD/TRL Exchange Rate. International Journal of Human and Social Sciences, 1(2), 111-116.

Andersen, T. G., \& Bollerslev, T. (1997). Heterogeneous Information Arrivals and Return Volatility Dynamics: Uncovering The Long-Run in High Frequency Returns. The Journal of Finance, 52(3), 975-1005. http://dx.doi.org/10.1111/j.1540-6261.1997.tb02722.x

Andreou, E., \& Ghysels, E. (2002). Detecting Multiple Breaks in Financial Market Volatility Dynamics. Journal of Applied Econometrics, 17(5), 579-600. http://dx.doi.org/10.1002/jae.684

Andrews, D. W. K., \& Guggenberger, P. (2003). A Bias-Reduced Log-Periodogram Regression Estimator for the Long-Memory Parameter. Econometrica, 71(2), 675-712. http://dx.doi.org/10.1111/1468-0262.00420

Antonakakis, N., \& Darby, J. (2013). Forecasting Volatility in Developing Countries Nominal Exchange Returns. Applied Financial Economics, 23(21), 1675-1691. http://dx.doi.org/10.1080/09603107.2013.844323

Bachelier, L. (1900). Théorie de la speculation. Annales Scientifiques de L'École Normale Supérieure, 17, 2186.

Bai, J., \& Perron, P. (1998). Estimating and Testing Linear Models with Multiple Structural Changes. Econometrica, 66(1), 47-78. http://dx.doi.org/10.2307/2998540

Bai, J., \& Perron, P. (2003). Computation and Analysis of Multiple Structural Change Models. Journal of Applied Econometrics, 18(1), 1-22. http://dx.doi.org/10.1002/jae.659

Baillie, R. T. (1996). Long memory processes and fractional integration in econometrics. Journal of Econometrics, 73, 5-59. http://dx.doi.org/10.1016/0304-4076(95)01732-1

Baillie, R. T., \& Morana, C. (2009). Modelling long memory and structural breaks in conditional variances: An adaptive FIGARCH approach. Journal of Economic Dynamics and Control, 33(8), 1577-1592. http://dx.doi.org/10.1016/j.jedc.2009.02.009

Baillie, R. T., Bollerslev, T., \& Mikkelsen, H. O. (1996). Fractionally integrated Generalized Autodaregressive Conditional Heteroscedasticity. Journal of Econometrics, $40.74, \quad 30$. http://dx.doi.org/10.1016/S0304-4076(95)01749-6

Balcilar, M. (2003). Long Memory and Structural Breaks in Turkish Inflation Rates. VI. National Econometrics 
and Statistics Symposium, 1-13.

Barkoulas, J. T., \& Baum, C. F. (1997). Long Memory and Forecasting in Euroyen Deposit Rates. Financial Engineering and the Japanese Markets, 4(3), 189-201. http://dx.doi.org/10.1023/A:1009630017314

Baum, C. F. (2000). Tests for stationarity of a time series. Stata Technical Bulletin, 36-46.

Black, F., \& Scholes, M. (1973). The pricing of options and corporate liabilities. Journal of Political Economy, 81(3), 637-654. http://dx.doi.org/10.1086/260062

Bollerslev, T., \& Mikkelsen, H. O. (1996). Modeling and Pricing Long Memory in Stock Market Volatility. Journal of Econometrics, 73(1), 151-184. http://dx.doi.org/10.1016/0304-4076(95)01736-4

Breidt, F. J., Crato, N., \& Lima, P. (1998). The detection and estimation of long memory in stochastic volatility. Journal of Econometrics, 83, 325-348. http://dx.doi.org/10.1016/S0304-4076(97)00072-9

Cevik, P., \& Emec, H. (2013). Long Memory Properties in Return and Volatility: An Application of the Impact of Arab Spring in Turkey Financial Market. Current Research Journal of Social Sciences, 5(2), 60-66.

Chambers, M. J. (1998). Long Memory and Aggregation in Macroeconomic Time Series. International Economic Review, 39(4), 1053-1072. http://dx.doi.org/10.2307/2527352

Choi, K., Yu, W. C., \& Zivot, E. (2010). Long memory versus structural breaks in modeling and Forecasting realized volatility. Journal of International Money and Finance, 29, 857-875. http://dx.doi.org/10.1016/j.jimonfin.2009.12.001

Chung, C. F., Hung, M. W., \& Liu, Y. H. (2003). Long Memory in Currency Futures Volatility. Research in Finance, 20, 139-158. http://dx.doi.org/10.1016/S0196-3821(03)20008-3

Comte, F., \& Renault, E. (1998). Long Memory in Continuous-Time Stochastic Volatility Models. Mathematical Finance, 8(4), 291-323. http://dx.doi.org/10.1111/1467-9965.00057

Conrad, C. (2010). Non-negativity Conditions for the Hyperbolic GARCH Model. Journal of Econometrics, 157(2), 441-457. http://dx.doi.org/10.1016/j.jeconom.2010.03.045

Crato, N., \& De Lima, P. J. F. (1994). Long-range dependence in the conditional variance of stock returns. Economics Letters, 45(3), 281-285. http://dx.doi.org/10.1016/0165-1765(94)90024-8

Dacorogna, M., Gençay, R., Muller, U. A., Pictet, O., \& Olsen, R. (2001). An Introduction to High-Frequency Finance. USA: Academic Press.

Davidson, J. (2004). Moment and Memory Properties of Linear Conditional Heteroscedasticity Models, and a New Model. Journal of Business and Economic Statistics, 22, 16-29. http://dx.doi.org/10.1198/073500103288619359

Diebold, F. X., \& Inoue, A. (2001). Long Memory And Regime Switching. Journal of Econometrics, 105(1), 131-159. http://dx.doi.org/10.1016/S0304-4076(01)00073-2

Ding, Z., Granger, C. W. J., \& Engle, R. E. (1993). A long memory property of stock market returns and a new model. Journal of Empirical Finance, 1(1), 83-106. http://dx.doi.org/10.1016/0927-5398(93)90006-D

Engle, R. F., \& Bollerslev, T. (1986). Modelling the Persistence of Conditional Variances. Econometric Review, 5(1), 1-50. http://dx.doi.org/10.1080/07474938608800095

Fama, E. (1965b). Random walks in stock market prices. Financial Analysts Journal, 21, 55-59. http://dx.doi.org/10.2469/faj.v21.n5.55

Fama, E. (1970). Efficient capital markets: a review of theory and empirical work. Journal of Finance, 25(2), 383-417. http://dx.doi.org/10.2307/2325486

Geweke, J., \& Porter-Hudak, S. (1983). The estimation and Appication of Long Memory Time Series Models. Journal of Time Series Analysis, 4(4), 221-238. http://dx.doi.org/10.1111/j.1467-9892.1983.tb00371.x

Giles, D. (2008). Some properties of absolute returns as a proxy for volatility. Applied Financial Economics Letters, 4(5), 347-350. http://dx.doi.org/10.1080/17446540701720709

Granger, C. W. J. (1980). Long memory relationships and the aggregation of dynamic models. Journal of Econometrics, 14, 227-238. http://dx.doi.org/10.1016/0304-4076(80)90092-5

Granger, C. W. J. (1981). Some properties of time series data and their use in econometric model specification. Journal of Econometrics, 16, 121-130. http://dx.doi.org/10.1016/0304-4076(81)90079-8 
Granger, C. W. J., \& Hyung, N. (2004). Occasional Structural Breaks and Long Memory with an Application to the S\&P 500 Absolute Stock Returns. Journal of Empirical Finance, 11(3), 399-421. http://dx.doi.org/10.1016/j.jempfin.2003.03.001

Granger, C. W. J., \& Joyeux, R. (1980). An introduction to loag memory time series models and fractional differencing. Journal of Time Series Analysis, $1, \quad$ 5-39. http://dx.doi.org/10.1111/j.1467-9892.1980.tb00297.x

Grau, P. (2005). Tests of Long Memory: A Bootstrap Approach. Computational Economics, 25(1-2), $103-113$. http://dx.doi.org/10.1007/s10614-005-6277-6

Guillaume, D. M., Dacorogna, M. M., Davé, R. R., Müller, U. A., Olsen, R. B., \& Pictet, O. V. (1997). From the Bird's Eye to the Microscope: A Survey of New Stylized Facts of the Intra-Daily Foreign Exchange Markets. Finance And Stochastics, 7(2), 95-129. http://dx.doi.org/10.1007/s007800050018

Han, Y. W. (2011). Structural Breaks and Long Memory Property in Korean Won Exchange Rates: Adaptive FIGARCH Model. Journal of East Asian Economic Integration, 15(2), 33-59. http://dx.doi.org/10.11644/KIEP.JEAI.2011.15.2.229

Hosking, J. R. M. (1981). Fractional differencing. Biometrika, 68, $165-176$. http://dx.doi.org/10.1093/biomet/68.1.165

Hurst, H. E. (1951). Long-term storage capacity of reservoirs. Transactions of the American Society of Civil Engineers, 116, 770-799.

Kasman, A., Kasman, S., \& Torun, E. (2009). Dual long memory property in returns and volatility: Evidence from the CEE countries' stock markets. Emerging Markets Review, 10, 122-139. http://dx.doi.org/10.1016/j.ememar.2009.02.002

Kılıç, R. (2004). On the long memory properties of emerging capital markets: evidence from Istanbul stock exchange. Applied Financial Economics, 14, 915-922. http://dx.doi.org/10.1080/0960310042000233638

Kilıç, R. (2011). Long Memory and Nonlinearity in Conditional Variances: A Smooth Transition FIGARCH Model. Journal of Empirical Finance, 18, 368-378. http://dx.doi.org/10.1016/j.jempfin.2010.11.007

Li, M., Li, W. K., \& Li, G. (2013). On Mixture Memory GARCH Models. Journal of Time Series Analysis, 34(6), 606-624. http://dx.doi.org/10.1111/jtsa.12037

Lien, D., \& Yang, L. (2010). The effects of structural breaks and long memory on currency hedging. Journal of Futures Markets, 30(7), 607-632.

Mandelbrot, B. B. (1963). The Variation of Certain Speculative Prices. Journal of Business, 36, 394-419. http://dx.doi.org/10.1086/294632

Mandelbrot, B. B. (1972). Statistical methodology for nonperiodic cycles: from the covariance to R/S analysis. Annals of Economic and Social Measurement, 1, 259-290.

Mandelbrot, B. B. (1983). The fractal geometry of nature. New York: W. H. Freeman.

Mandelbrot, B. B., \& Van Ness, J. W. (1968). Fractional Brownian motions, fractional noises and applications. SIAM Review, 10(4), 422-437. http://dx.doi.org/10.1137/1010093

Markowitz, H. (1952). Portfolio selection. The Journal of Finance, 12(7), 77-91.

Mishra, T. K., \& Urbain, J. P. (2004). Long Memory Characteristics of Demographic Components: Implications for Development $\quad$ Objectives. $\quad$ Retrieved from http://www.gate.cnrs.fr/t2m2005/Textes\%20des\%20communications/C3.pdf

Niquez, T. M., \& Rubia, A. (2006). Forecasting the conditional covariance matrix of a portfolio under long-run temporal dependence. Journal of Forecasting, 25, 439-458. http://dx.doi.org/10.1002/for.997

Ohanissian, A., Russell, J. R., \& Tsay, R. S. (2008). True or Spurious Long Memory? A New Test. Journal of Business and Economic Statistics, 26, 161-75. http://dx.doi.org/10.1198/073500107000000340

Pagan, A. R., \& Schwert, G. W. (1990). Alternative Models For Conditional Stock Volatility. Journal of Econometrics, 45, 267-290. http://dx.doi.org/10.1016/0304-4076(90)90101-X

Phillips, P. C. B. (1999a). Discrete Fourier transforms of fractional processes. Unpublished working, Paper No. 1243, Cowles Foundation for Research in Economics, Yale University. Retrieved from http://cowles.econ.yale.edu/P/cd/d12a/d1243.pdf 
Phillips, P. C. B. (1999b). Unit Root Log Periodogram Regression. Unpublished working paper No. 1244, Cowles Foundation for Research in Economics, Yale University. Retrieved from http://cowles.econ.yale.edu/P/cd/d12a/

Robinson, P. M. (1994). Efficient Tests of Nonstationary Hypotheses. Journal of the American Statistical Association, 89, 1420-1437. http://dx.doi.org/10.1080/01621459.1994.10476881

Sharpe, W. F. (1964). Capital Asset Prices: A Theory of Market Equilibrium Under Conditions of Risk. Journal of Finance, 19, 425-442.

Shi, Y., \& Ho, K. Y. (2013). Modelling High-Frequency Volatility with Three-State FIGARCH models. 20th International Congress on Modelling and Simulation, 1385-1391.

Smith, A. (2005). Level Shifts and the Illusion of Long Memory in Economic Time Series. Journal of Business \& Economic Statistics, 23(3), 321-335. http://dx.doi.org/10.1198/073500104000000280

Triacca, U. (2007). On the variance of the error associated to the squared return as proxy of volatility. Applied Financial Economics Letters, 3(4), 255-257. http://dx.doi.org/10.1080/17446540601118343

Ural, M. C., \& Küçüközmen, C. (2011). Analyzing the Dual Long Memory in Stock Market Returns. Ege Academic Review, 11, 19-28.

Wang, W. (2006). Stochasticity, Nonlinearity and Forecasting of Streamflow Processes. Netherlands: Delft University Press.

Yang, B. (2008). LRD of Fractional Brownian Motion and Application in Data Network. Retrieved from http://math.arizona.edu/ flaschka/Topmatter/527files/termpapers/bole.pdf

Zhang, A., Gabrys, R., \& Kokoszka, P. (2007). Discriminating between Long Memory and Volatility Shifts. Austrian Journal of Statistics, 36(4), 253-275.

\section{Copyrights}

Copyright for this article is retained by the author(s), with first publication rights granted to the journal.

This is an open-access article distributed under the terms and conditions of the Creative Commons Attribution license (http://creativecommons.org/licenses/by/3.0/). 